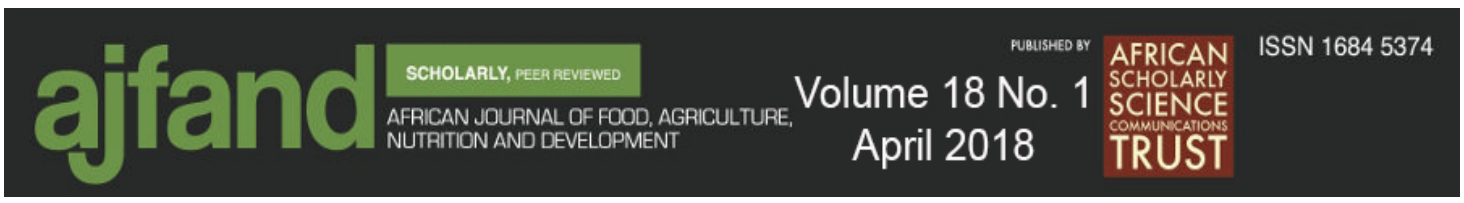

Afr. J. Food Agric. Nutr. Dev. 2018; 18(1): 13239-13253

DOI: 10.18697/ajfand.81.17635

\title{
PROXIMATE COMPOSITION AND NUTRITIONAL CHARACTERIZATION OF CHIA ENRICHED YOGHURT
}

Kibui $\mathrm{AN}^{* 1}$, Owaga $\mathrm{E}^{1}$ and $M$ Mburu ${ }^{1}$

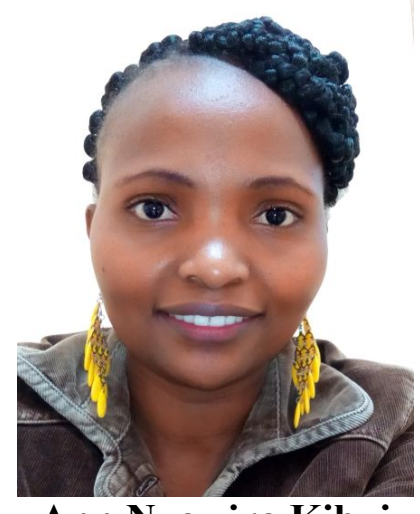

Ann Nyawira Kibui

*Corresponding author email: nyakazikib@gmail.com

${ }^{1}$ Institute of Food Bioresources Technology, Dedan Kimathi University of Technology, P. O. Box 657-10100 Nyeri, Kenya 


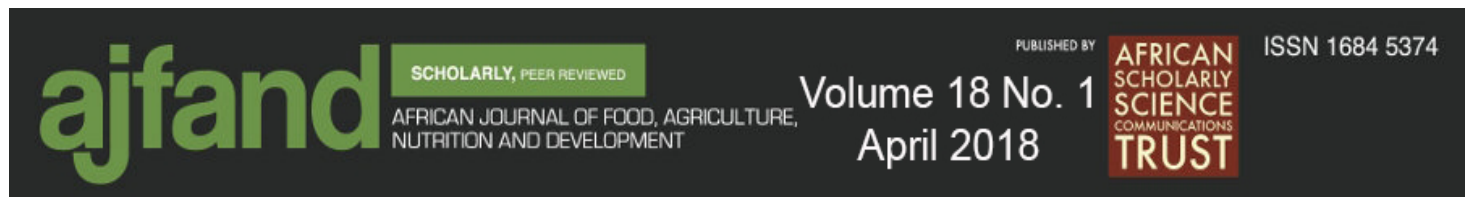

\section{ABSTRACT}

Yoghurt is a fermented dairy product associated with several beneficial nutritional and health effects. Due to increased demand of yoghurt in Kenya, some processors seek to incorporate synthetic ingredients in order to improve the nutritional value, thickening and stabilizing properties. Besides having good gelling properties, chia seeds (Salvia hispanica L.) are a good source of proteins, omega-3 fatty acids, omega- 6 fatty acids, minerals, soluble dietary fiber and phytochemicals. This study sought to develop and determine the proximate composition and nutritional (amino acids, fatty acids, and mineral contents) characteristics of chia enriched yoghurt (CEY). Yoghurt treatments were enriched with chia seeds at either $1.5 \% \mathrm{~m} / \mathrm{v}(\mathrm{CEY} 1.5), 2.5 \% \mathrm{~m} / \mathrm{v}(\mathrm{CEY} 2.5)$ or $3.5 \%$ $\mathrm{m} / \mathrm{v}$ (CEY3.5), and 2\% cornstarch (CEY0). The results of the proximate composition indicated a significantly higher content of moisture, crude ash, crude fat, crude fiber and carbohydrates in CEY1.5, CEY2.5 and CEY3.5 than in CEY0. In the current study, the composition of calcium, potassium, and phosphorus, was significantly higher in CEY 1.5, CEY2.5 and CEY3.5 than in CEY0, with values increasing with increase in quantity of chia seeds in the formulation. The results for amino acids showed that the essential and non-essential amino acids were significantly higher in CEY3.5 than CEY2.5, CEY2.5 than CEY1.5 and CEY1.5 than CEY0. In terms of fatty acids profile, the concentration of lauric acid and palmitic acid was significantly lower in CEY1.5, CEY2.5 and CEY3.5 than in CEY0. On the other hand, the concentration of stearic acid, oleic acid, linoleic acid and $\alpha$-linolenic acid in CEY1.5, CEY2.5 and CEY3.5 was significantly higher than in CEY0. In conclusion, CEY1.5, CEY2.5 and CEY3.5 showed enhanced proximate composition and nutritional (amino acids, fatty acids, and minerals contents) characteristics compared to CEY0, thus chia seeds have a potential to be used in yoghurt for value addition.

Key words: Chia, yoghurt, fatty acids, amino acids, enrichment, minerals, proximate composition 


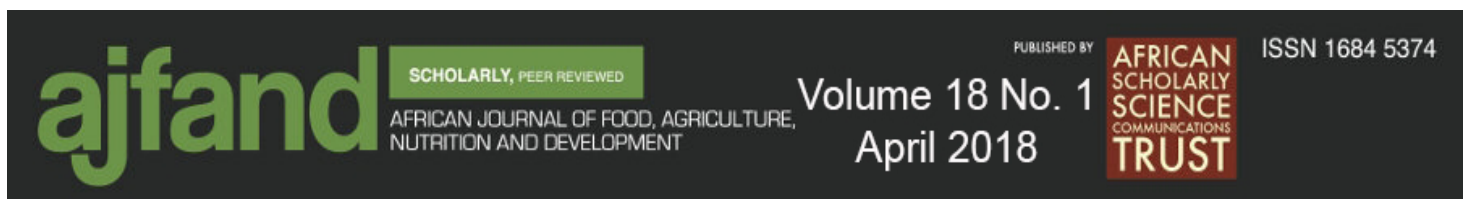

\section{INTRODUCTION}

Kenya's economy depends heavily on agriculture and its dairy sector is among the largest industries, dealing with dairy products in sub-Saharan Africa [1].There is an increased market demand for functional foods such as yoghurt due to increased awareness of their health benefits. The dairy industry in Kenya has a potential to produce functional dairy products either with probiotic organisms, specific macronutrients or micronutrients. Yoghurt has long been recognized as a functional food due to its contribution to health benefits to the digestive system and is among the leading preferred vehicles for probiotic culture. With the continuing rise in the popularity of probiotic yoghurt, dairy-based food manufacturers are continuously evaluating novel ingredients that would enhance health benefits and sensory properties of yoghurt [2]. As a result, utilization of various synthetic and highly processed ingredients in yoghurt production is a common phenomenon. In a bid to enhance the health effect and consumer's interests, yoghurt has been modified with different ingredients such as pomegranate (Punica gratanum L.) fruit peels [3], and tea catechins [4].

Chia (Salvia hispanica L.), is an exotic plant which has recently been introduced in Kenya and is gaining popularity among consumers using the seeds in drinking water, and other food blends. Chia seed is increasingly receiving recognition as a good source of omega-3/omega-6 fatty acids, soluble dietary fiber, proteins as well as phytochemicals [5]. Utilization of olein fraction of chia seed oil into ice cream significantly improved the concentration of omega-3 fatty acids such as alpha-linolenic acid (ALA), eicosapentaenoic acid (EPA), docosapentaenoic acid (DPA) and docosahexaenoic acid (DHA) in the enriched ice cream [7]. Chia has functional properties towards prevention of several non-communicable diseases like obesity, cardiovascular diseases, cancer and diabetes which are commonly found among communities [5].

Chia seed gum, contained in the seed coat or adjacent layer, begins to form as seeds are placed in water [6] and hence can be used for thickening as well as a stabilizer in food products. In addition, the slimy properties of chia gum manifests even at very low concentrations. Therefore, incorporation of chia seeds could enhance the nutritional and functional value of yoghurt. Therefore, the aim of this study was to investigate the proximate composition and the nutritional characteristics of chia enriched yoghurt.

\section{MATERIALS AND METHODS}

A laboratory-based experimental method was used for this study. To collect both qualitative and quantitative data in this study, all the experiments were carried out under laboratory conditions while still observing the technological conditions and requirements for industrial yoghurt production. The experiment was designed to have four treatments where varying quantities of chia seeds were randomly assigned to the treatments for the preliminary work. For this study, each treatment consisting of chia enriched yoghurt (CEY) made from whole milk with varied proportions chia seeds $(1.5 \% \mathrm{~m} / \mathrm{v}$ for CEY 1.5 , $2.5 \%$ for CEY2.5 and 3.5\% for CEY3.5) and corn starch at 2\% (CEY0) was investigated in triplicate. 


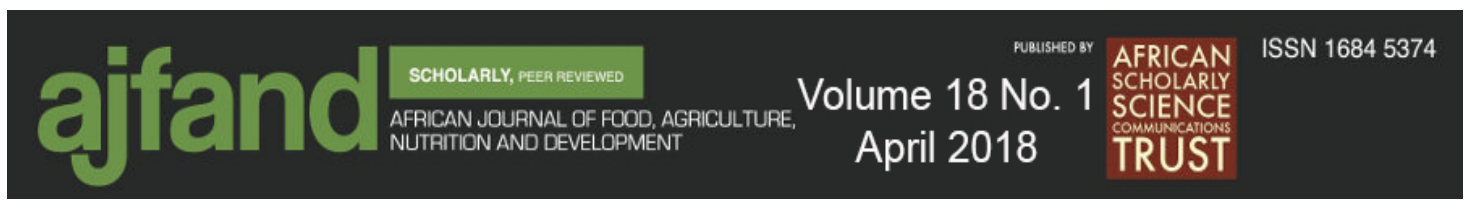

\section{Sample collection and storage}

The dried mixture of white and black chia seeds was purchased from a farmer based at King'ong'o, Nyeri County, Kenya. Fresh whole milk was obtained from the Dedan Kimathi University of Technology dairy farm. The chia seeds were stored in sample bags in a cool dry place, while the fresh milk was refrigerated at $4^{\circ} \mathrm{C}$ until use. The starter culture was purchased from Promaco Limited, in Nairobi, Kenya and stored at $-20^{\circ} \mathrm{C}$.

\section{Preparation of chia seeds}

The chia seeds were cleaned by hand picking out all the unwanted materials before putting them in sterile bags where they were stored in a cool dry place until use.

\section{Production of chia enriched yoghurt}

Dry ingredients (chia seeds and sugar) were weighed and mixed thoroughly with a little whole milk, to prevent formation of lumps. The remaining whole cows' milk was heated to $55^{\circ} \mathrm{C}$ and the mixture of dry chia seeds and sugar added while stirring. The concentrated mixture was heated to $85^{\circ} \mathrm{C}$ for 30 minutes and then cooled to $45^{\circ} \mathrm{C}$. The starter culture (Streptococci thermophillus and Lactobacillus delbruckii bulgaricus) was then added at $2 \mathrm{~g} / \mathrm{L}$ and the mixture incubated at $45^{\circ} \mathrm{C}$ for 3.5 hours. The yoghurt was then cooled to $4^{\circ} \mathrm{C}$ and refrigerated for 12 hours before breaking the coagulum. The yoghurt was later packaged in sterilized bottles and stored at $-22^{\circ} \mathrm{C}$ pending analysis for nutritional and chemical composition.

\section{Nutritional and caloric value analysis of chia seeds and chia enriched yoghurt samples}

The moisture content of the samples was determined according to AOAC, method 2001.12 [8]. The ash content of each sample was determined according to AOAC, method 923.03 [8]. The protein content $(\mathrm{N}$ x 6.38) was determined using Semi-Micro Kjeldahl Method as described by AOAC method 992.23 [8]. Crude fat content was determined by the Soxhlet method [8]. The crude fiber content of the samples was determined as the fraction remaining after digestion with concentrated sulphuric acid and potassium hydroxide in the presence of a foam-suppressor, in a fume hood [9]. The carbohydrate content of the samples was determined by estimation using the arithmetic difference method [10]. The caloric value of the samples was calculated using the method from the Atwater coefficients [11].

For determination of amino acids, extraction was performed [12] and the samples were analyzed using Gas Chromatography-Mass Spectrometry (GC-MS). Free fatty acids profile was determined using gas chromatography [8]. The iron (Fe), zinc $(\mathrm{Zn})$, calcium $(\mathrm{Ca})$, manganese $(\mathrm{Mn})$, magnesium $(\mathrm{Mg})$ potassium $(\mathrm{K})$, and sodium $(\mathrm{Na})$ profile were determined using Atomic Absorption Spectrophotometer (AAS) [13] with modification while phosphorus was determined by colorimetric method [14]. 


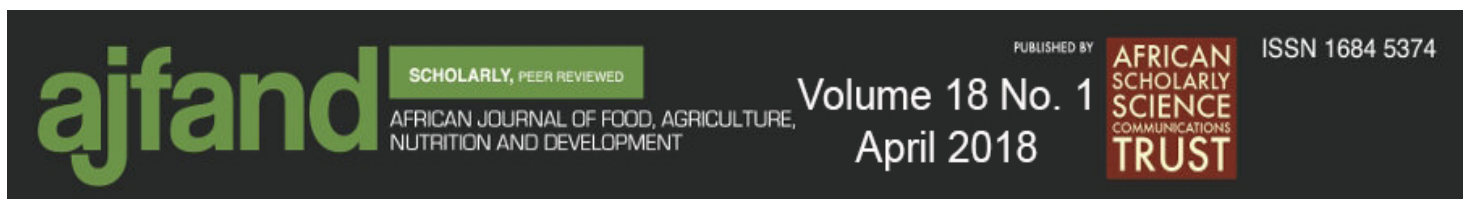

\section{RESULTS AND DISCUSSION}

\section{Proximate composition and calorific value analysis}

Results of proximate composition are reported in Table 1 . The average moisture content for the chia seeds was $5.16 \%$, which was slightly lower than the value of $6.3 \%$ reported by a previous study [11]. This variation could be due to the different climatic conditions of growth as well as the degree of drying applied by the farmers. Sample CEY0 had the highest moisture content of $81.95 \%$, which fell within the range of most yoghurts available in the market (80-86\%) [15]. The moisture content for all the enriched samples was significantly lower than that of CEY 0 and the variance between them was dependent on the quantity of chia seeds used in the formulation. This could be supported by a study done on hydration of chia mucilage [16], which concluded that a $100 \mathrm{mg}$ sample of mucilage has the ability to absorb $2.7 \mathrm{~g}$ of water, which is 27 times its weight. This effect could, therefore, explain the lower moisture content in the yoghurt samples containing chia seeds.

On ash content, chia seeds had an average $4.45 \%$ (Table 1), a value that is similar to the one reported in literature [11]. The ash content is a reflection of the amount of minerals in a food material [17]. The ash content in yoghurt samples ranged from $0.52 \%$ in CEY0 to $1.10 \%$ in CEY3.5. The results also indicated that the ash content increased as the proportion of chia seeds increased in the yoghurt samples due to the fact that chia seeds, by implication, have high ash content and minerals $[3,8]$.

The crude protein content of chia seeds $(20.90 \%)$, as shown in Table 1 , was found to be higher than those reported by two studies as 19.6\% [11] and $16.54 \%$ [5], but are within the range given in another study of $15-26 \%$ [18]. The crude fat content in chia seeds was $29.06 \%$ as shown in Table 1 . This amount was lower than the value of $34.4 \%$ reported in a previous study [11], but was within the range of $20.3 \%$ to $33.6 \%$ reported in literature [19]. Grain oil yield ranges from $29.4 \%$ to $33.5 \%$ depending on the area of origin of the chia, climatic conditions and the technique used for its extraction [20]. The results show a proportional relationship between increased fat content and increased chia seeds concentration where CEY3.5 had the highest fat content while CEY1.5 had the lowest. This fluctuation of fat content is justified by the high fat content reported for the chia seeds. The data indicates a major difference in fat content between CEY0 and chia enriched samples (CEY1.5, CEY2.5 and CEY3.5). Fat content in yoghurt could have a positive influence on the sensory and physical characteristics [21] as well as a negative impact on the shelf stability [22]. In yoghurt, fat plays an important role in improving its consistency [23]. The protein and oil contents, as well as fatty acid composition of chia seeds, vary significantly with the location and climatic condition of growth [20].

Chia seeds had a crude fiber content of $21.14 \%$ (Table 1). This amount was lower than previous reports which indicated between 34 and $40 \%$ of dietary fiber in chia seeds, equivalent to $100 \%$ of the daily recommendations for the adult population. The defatted flour possessed $40 \%$ fiber, $5-10 \%$ of which is soluble and forms part of the mucilage [24]. The results indicate that there was a significant increase $(p<0.05)$ in fiber content among the chia enriched yoghurts compared to CEY0. The recommended dietary fiber intakes for children and adults are $14 \mathrm{~g} / 1000 \mathrm{kcal}$ [25], and enriching yoghurt with chia 


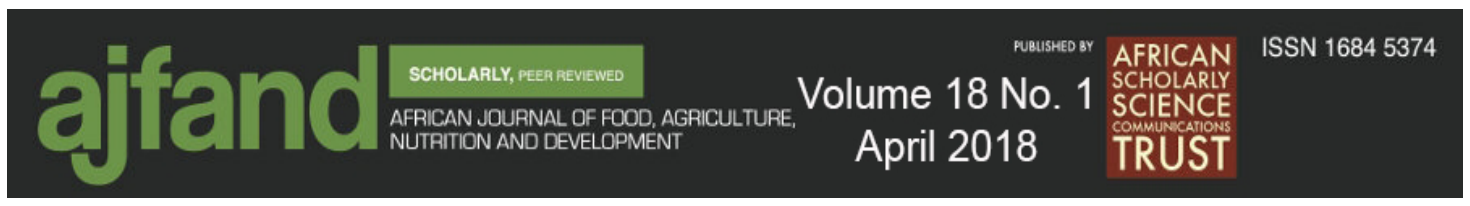

seeds may contribute a significant amount to this. The carbohydrate content of the yoghurt samples ranged from $1.16 \%$ in CEY3.5 and $1.85 \%$ in CEY0. The low carbohydrate content was expected since most of the available lactose in the yoghurt had been converted to lactic acid, making yoghurt an ideal food for people with lactose intolerance [23].

\section{Nutritional analysis of chia seeds and chia enriched yoghurt Amino acids profile}

The lysine content of chia seeds was $0.73 \mathrm{~g} / 100 \mathrm{~g}$ protein (Table 2), a value that was lower than the value of $0.97 \mathrm{~g} / 100 \mathrm{~g}$ recorded in literature $[3,22]$. Chia seeds appear to have an impact on the concentration of lysine in yoghurt since the results ranged from $3.22 \mathrm{~g} / 100 \mathrm{~g}$ in CEY0 to $5.38 \mathrm{~g} / 100 \mathrm{~g}$ in CEY3.5. Histidine content of chia seeds was 0.33 $\mathrm{g} / 100 \mathrm{~g}$ which was within the range of $0.25 \mathrm{~g} / 100 \mathrm{~g}$ to $0.32 \mathrm{~g} / 100 \mathrm{~g}$ [18], while other studies reported a value of $0.53 \mathrm{~g} / 100 \mathrm{~g}$ [3, 22]. For the yoghurt samples, the content of histidine ranged from $2.60 \mathrm{~g} / 100 \mathrm{~g}$ in CEY0 to $3.98 \mathrm{~g} / 100 \mathrm{~g}$ in CEY3.5.

Chia seeds had threonine content of $0.4 \mathrm{~g} / 100 \mathrm{~g}$. This value was similar to the values reported in the literature ranging from $0.32 \mathrm{~g} / 100 \mathrm{~g}$ to $0.43 \mathrm{~g} / 100 \mathrm{~g}$ [18]. The results further show that the threonine content in the yoghurt samples ranged from $2.65 \mathrm{~g} / 100 \mathrm{~g}$ in CEY0 to $4.65 \mathrm{~g} / 100 \mathrm{~g}$ in CEY3.5, an indication that the amino acid may have continued to increase during fermentation. The threonine content differed significantly among all the yoghurt samples. The results illustrated that the content of valine in chia seeds was $0.62 \mathrm{~g} / 100 \mathrm{~g}$, hence differing from the value of $0.95 \mathrm{~g} / 100 \mathrm{~g}$ reported in previous studies $[3,22]$. The values in the literature range from $0.51 \mathrm{~g} / 100 \mathrm{~g}$ to $0.63 \mathrm{~g} / 100 \mathrm{~g}$ [18]. Chia seeds were shown to contain $0.52 \mathrm{~g} / 100 \mathrm{~g}$ of methionine, a value that is similar to the ones reported in previous studies $[3,22]$. The concentration of methionine in the yoghurt samples ranged from $1.15 \mathrm{~g} / 100 \mathrm{~g}$ in CEY0 to $2.69 \mathrm{~g} / 100 \mathrm{~g}$ in CEY3.5. The statistical analysis showed that all the samples differed significantly $(p<0.05)$ in methionine content, an indication that chia had a direct impact on the improved yoghurt. Isoleucine content in chia seeds was $0.54 \mathrm{~g} / 100 \mathrm{~g}$, a value that was in agreement with the range of $0.32 \mathrm{~g} / 100 \mathrm{~g}$ to $0.40 \mathrm{~g} / 100 \mathrm{~g}$, as recorded in the literature according to [18]. The isoleucine content ranged between $2.56 \mathrm{~g} / 100 \mathrm{~g}$ in CEY0 and $3.43 \mathrm{~g} / 100 \mathrm{~g}$ in CEY3.5. The current study observed that the leucine content of chia seeds was $1.02 \mathrm{~g} / 100 \mathrm{~g}$, which was lower than the value of $1.37 \mathrm{~g} / 100 \mathrm{~g}$ earlier reported $[3,22]$. These values are higher than the range given in literature as $0.60 \mathrm{~g} / 100 \mathrm{~g}$ to $0.73 \mathrm{~g} / 100 \mathrm{~g}$ [18]. The results of the concentration of leucine ranged between $7.56 \mathrm{~g} / 100 \mathrm{~g}$ in CEY0 and $9.54 \mathrm{~g} / 100 \mathrm{~g}$ in CEY3.5.

Phenylalanine content in chia seeds was $0.75 \mathrm{~g} / 100 \mathrm{~g}$, a value that is slightly lower than the values $(1.02 \mathrm{~g} / 100 \mathrm{~g})$ documented in literature $[3,22]$. The literature records values that range between $0.47 / 100 \mathrm{~g}$ to $0.59 \mathrm{~g} / 100 \mathrm{~g}$ that are lower than these findings [18]. Regarding phenylalanine content in the yoghurt samples, the results showed a range of $3.97 \mathrm{~g} / 100 \mathrm{~g}$ in CEY0 to $4.20 \mathrm{~g} / 100 \mathrm{~g}$ in CEY3.5. This observation suggests that chia seeds did not affect the concentration of the amino acid in yoghurt. The only nonessential amino acids that were detected in chia seeds in the current study were arginine $(0.74 \mathrm{~g} / 100 \mathrm{~g})$, aspartic acid $(0.58 \mathrm{~g} / 100 \mathrm{~g})$ and glutamic acid $(4.36 \mathrm{~g} / 100 \mathrm{~g})$. These results differed from reported values (arginine at $2.14 \mathrm{~g} / 100 \mathrm{~g}, 1.69 \mathrm{~g} / 100 \mathrm{~g}$ for aspartic acid and 


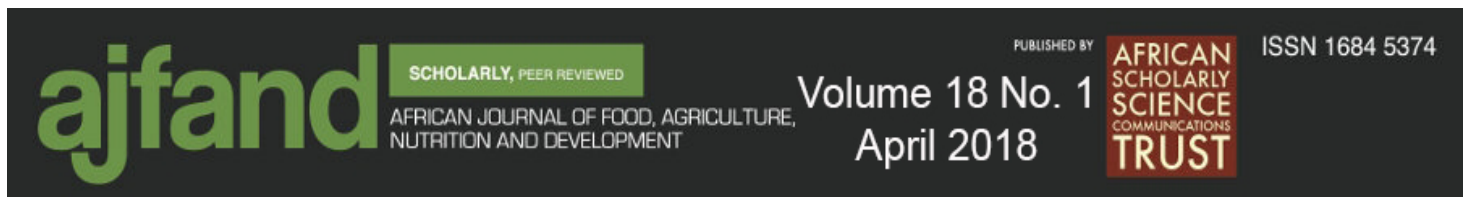

$3.50 \mathrm{~g} / 100 \mathrm{~g}$ for glutamic acid) [24]. Significant quantities of the other non-essential amino acids were reported $[3,22]$. However, significant differences in the concentration of the non-essential amino acids were observed among all the yoghurt samples as their values increased with increase in the amount of chia added in the chia enriched yoghurt. The levels of amino acids in all the chia enriched yoghurt samples were significantly higher than CEY0 ( $>0.05)$. There is limited literature on chia seeds proteins and the influence of the extraction process and storage on the amino acids profile.

\section{Fatty acids profile}

The results for the fatty acid composition ( $\%$ of total fatty acids) are reported in Table 3 . The fatty acids composition of chia seed is influenced by numerous factors, including seed variety, size reduction practices, pretreatment method and seed storage conditions [24]. The results show that Caprylic acid, 10:0 and pentadecanoic acid went undetected in chia seeds, hence these are not discussed here. Given that chia seed oil is a natural product, its chemical composition may vary depending on a number of factors such as the extraction system and the cultivation environment [19].

The current study found that concentration of myristic acid $(0.05 \%)$ in chia seeds was close to the documented value of $0.03 \%$ [11]. In the yoghurt samples, its concentration ranged from $12.07 \%$ in CEY3.5 to $12.35 \%$ in CEY0. There was no significant difference $(p<0.05)$ in concentration of myristic acid between CEY0 and the other CEYs, where its concentration decreased with the increase of chia seeds in the yoghurt formulation. This showed that chia seeds decreased the concentration of myristic acid in yoghurt though not significantly.

In the present study, chia seeds contained $7.15 \%$ of palmitic acid, a value close to the reported values of 7\% [11]; and 6.8\% [24]. The results show that the concentration of palmitic acid in yoghurt formulations decreased with increase in the amount of chia seeds used in the formulation, as it ranged from $34.45 \%$ in CEY0 to $29.13 \%$ in CEY3.5. There were significant differences in the concentration of palmitic acid between CEY0 and all the chia enriched yoghurt samples (Table 3). This could mean that the chia seeds influenced the concentration of the fatty acid in yoghurt. Being a saturated fatty acid, palmitic acid is stable to oxidation and heat [26], and it is the most representative fatty acid in cow's milk fat. In the present study, the concentration of palmitoleic acid in chia seeds $(0.03 \%)$ was similar to a documented value of $0.09 \%$ [11]. The concentration of palmitoleic acid CEY0 $(0.29 \%)$ was not significantly different from that of CEYs $(0.23 \%$ in CEY1.5, $0.22 \%$ in CEY2.5, 0.22\% in CEY3.5). This could have been influenced by the low concentration of palmitoleic acid in the chia seeds. Caprylic acid was $3.31 \%$ in chia seeds, a value that was very close to the value of $3.23 \%$ [11]. The fatty acid was reported at $11.69 \%$ in CEY0, a value that was not significantly different from $12.09 \%$ in CEY 1.5 , $12.36 \%$ in CEY2.5 and $12.41 \%$ in CEY3.5. Caprylic acid is documented as a fairly stable saturated fatty acid with an 18-carbon chain [26] and enrichment of yoghurt with chia seeds caused significant differences in concentration of caprylic acid in yoghurt. Its concentration increased with the increase in the amount of chia seeds in the yoghurt formulations.

The current study reported the content of oleic acid in chia seeds as 7.19\% (Table 3), a value similar to a reported value of $7.19 \%$ [27], although slightly higher values of $7.48 \%$ and $8.3 \%$ are documented in previous studies $[8,22]$. This could be attributed to the difference in cultivation regions which has been reported as factor that is likely to influence fatty acids 


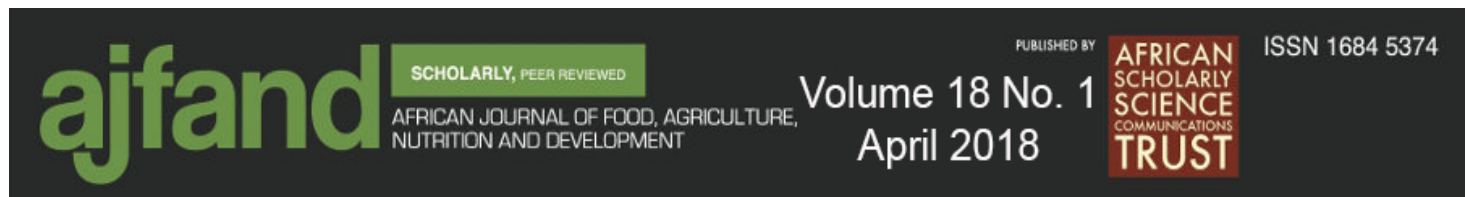

composition [11]. The concentration of oleic acid in CEY0 (24.49\%) was significantly different from CEYs, which ranged from 25.23\% in CEY1.5 and 25.86\% in CEY3.5 (Table 3). This served as an indication that chia seeds influenced the concentration of oleic acid in yoghurt.

A significant concentration of linoleic acid (18.39\%) was detected in chia seeds, a value close to $20.47 \%$ reported in a previous study [11], although a reasonably lower value $(12.14 \%)$ has been reported [28]. The concentration of linoleic acid was not significantly different in CEY0 (4.60\%) than in CEY1.5 (4.72\%), although significant difference was observed in its concentration in CEY2.5 (4.92\%) and CEY3.5 (5.04\%). However, the concentration of linoleic acid was on an upward trend as the chia seeds concentration increased. Linoleic acid is also known as omega-6 fatty acid and is a polyunsaturated fatty acid (PUFA) which mainly occurs in plant glycosides. Its first double bond is located between the sixth and seventh carbon atom from the methyl end of the fatty acid. In human nutrition, linoleic acid is an essential fatty acid since it cannot be synthesized by the body. It is used in the biosynthesis of cellular membranes and prostaglandins [29].

In the current study, $\alpha$ linoleic acid was detected by gas chromatography in chia seeds at a concentration of $63.10 \%$ which was found to be close to a documented level of $62.02 \%$ [11]. Among the yoghurt samples, the present study showed that the concentration of $\alpha$ linoleic acid in yoghurt samples ranged from $2.97 \%$ in CEY0 to $8.10 \%$ in CEY3.5. Chia seeds appeared to significantly increase the concentration of this fatty acid in yoghurt, leading to significant differences in its concentration among all the samples. However, the quantity did not correspond with the high amount of $\alpha$ linoleic acid in chia seeds (63.10\%). This could be due to the low quantity of chia seeds used and also partly due to loss during the extraction and methylation since the fatty acid is a long chain fatty acid [19].

The level of arachidic acid detected in the chia seeds $(0.35 \%)$ was lower than the $0.42 \%$ previously reported [27], although the documented levels of the fatty acid have been within the range of $1.0-1.1 \%$ of the raw chia fat [27]. Statistical analysis did not detect any significant differences in the concentration of arachidic acid in all the yoghurt samples, possibly due to the low concentration of the fatty acid in chia seeds. This could be relating to the fact that the concentration ( $1.5 \%$ to $3.5 \% \mathrm{~m} / \mathrm{v})$ was low and just a few seeds were in the yoghurt formulations.

The results of fatty acids concentration in chia seeds in the present study tend to agree with most authors who claim that the composition of oil in seeds, measured as percent fatty acids, is influenced by the location of seed cultivation $[8,28]$. The variations in most of the fatty acids may be the result of seasonal differences, batch differences and varied cultivation conditions [27]. The incorporation of chia seed oil into the diet would be very beneficial since the polyunsaturated fatty acids present in plant oils are reported to provide several health benefits $[17,28]$.

\section{Mineral content}

Results of mineral content of chia seeds and chia enriched yoghurt are shown in Table 4. The calcium content was $1226 \mathrm{mg} / \mathrm{kg}$, a value that is higher than those reported in previous studies; 557 to $770 \mathrm{mg} / 100 \mathrm{~g}$ [18] and $951.20 \mathrm{mg} / \mathrm{kg}$ [27]. The high calcium level may be explained by variations in cultivation conditions and location [27]. There was also a high content of calcium in CEY3.5 $(1616 \mathrm{mg} / \mathrm{kg})$ compared to all the other 


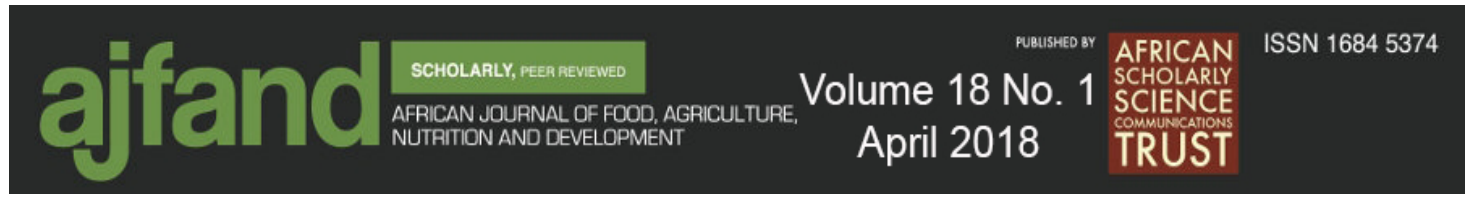

yoghurt samples. The reported calcium content for plain yoghurts is about $1950 \mathrm{mg} / \mathrm{kg}$ [31]. Calcium plays key roles in bone formation and mineralization. The calcium requirements during growth, pregnancy, and lactation are increased [32]. This, therefore, means that the chia enriched yoghurt would be a beneficial drink for the children, pregnant and lactating mothers as well as the elderly whose calcium requirement is high.

The chia seeds contained $701 \mathrm{mg} / \mathrm{kg}$ of potassium (Table 4), which was within the previously reported range of $667-809 \mathrm{mg} / \mathrm{kg}$ [18]. The results indicated a higher potassium content in CEY3.5 with a value of $745 \mathrm{mg} / \mathrm{kg}$. The sample with CEY0 was reported to contain $690 \mathrm{mg} / \mathrm{kg}$ while a previous research show a varying potassium content in plain yoghurt of $541 \mathrm{mg} / \mathrm{kg}$ [31].

Potassium helps the nerves to function and muscles to contract as well as helping with normal heartbeat, increasing iron utilization [33], and is beneficial to people taking diuretics to control hypertension who suffer from excessive excretion of potassium through the body fluid [17]. Chia seeds were found to contain $214 \mathrm{mg} / \mathrm{kg}$ of magnesium, a lower content compared to the range of $325-390 \mathrm{mg} / \mathrm{kg}$ reported in a previous study [18]. Magnesium content may have been compensated by the high calcium content in the chia seeds as it was slightly higher in CEYs. It was noted that the magnesium content gradually increased with increase in the percent of the chia seeds in yoghurt samples. This indicated that chia seeds impacted the nutritional quality of the yoghurt by increasing the content of nutritional magnesium, which is an important mineral in human nutrition [34]. Despite the low content of iron in chia seeds $(9 \mathrm{mg} / \mathrm{kg})$, a slight increase was observed in the results for the chia enriched yoghurt. It is, however, within the reported range of 6.3 to $9.9 \mathrm{mg} / \mathrm{kg}$ [18]. The iron content of the yoghurt samples enriched with chia seeds increased with increase of chia seeds content in the formulation. Zinc content of chia seeds was $6 \mathrm{mg} / \mathrm{kg}$, a value that is higher than the documented range which ranges from $<0.1$ to $4.95 \mathrm{mg} / \mathrm{kg}$ in different regions [18]. There was a significant difference between the zinc content in CEY0 and in other CEYs. The manganese content for chia seeds was $8 \mathrm{mg} / \mathrm{kg}$ while phosphorus content was $116 \mathrm{mg} / \mathrm{kg}$. The samples with the highest phosphorus content were CEY2.5 and CEY3.5 $(390 \mathrm{mg} / \mathrm{kg}$ and $397 \mathrm{mg} / \mathrm{kg}$, respectively). The high phosphorus content is desirable as it increases bone health among humans [35]. Copper content in chia seeds was $6 \mathrm{mg} / \mathrm{kg}$ in both wet and dry basis, a value that is significantly higher than the reported range from 0.2 to $1.94 \mathrm{mg} / \mathrm{kg}$ [18].

\section{CONCLUSION}

All chia enriched yoghurt samples (CEY1.5, CEY2.5 and CEY3.5) showed enhanced proximate composition and nutritional (amino acids, fatty acids, and minerals contents) characteristics compared to CEY0, thus chia seeds have a potential to be used in yoghurt for value addition. Further experiments are recommended to examine the phenolic compounds in chia enriched yoghurt as well as to determine their activities in yoghurt. 


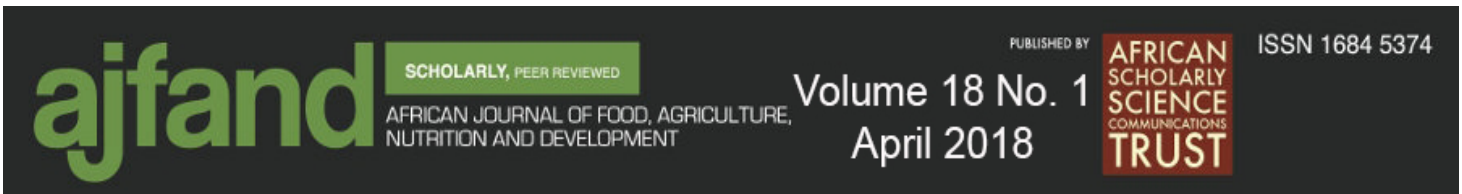

Table 1: Proximate composition (\%) of chia seeds and chia enriched yoghurt (CEY)

\begin{tabular}{lrrrrr}
\hline Component & Chia seeds & \multicolumn{1}{l}{ CEY0 } & \multicolumn{1}{l}{ CEY1.5 } & \multicolumn{1}{l}{ CEY2.5 } & \multicolumn{1}{c}{ CEY3.5 } \\
\hline Moisture (\%) & $5.16 \pm 0.10$ & $81.95 \pm 0.03^{\mathrm{a}}$ & $79.39 \pm 0.07^{\mathrm{b}}$ & $78.81 \pm 0.13^{\mathrm{c}}$ & $77.61 \pm 0.84^{\mathrm{d}}$ \\
Crude ash (\%) & $4.45 \pm 0.21$ & $0.52 \pm 0.03^{\mathrm{a}}$ & $0.71 \pm 0.07^{\mathrm{a}}$ & $0.87 \pm 0.11^{\mathrm{a}}$ & $1.10 \pm 0.11^{\mathrm{a}}$ \\
Crude proteins (\%) & $20.90 \pm 0.44$ & $4.29 \pm 0.39^{\mathrm{a}}$ & $4.30 \pm 0.47^{\mathrm{a}}$ & $4.37 \pm 0.12^{\mathrm{a}}$ & $4.40 \pm 0.59^{\mathrm{a}}$ \\
Crude lipids (\%) & $29.06 \pm 0.01$ & $12.40 \pm 0.36^{\mathrm{a}}$ & $14.00 \pm 0.11^{\mathrm{b}}$ & $14.77 \pm 0.26^{\mathrm{b}}$ & $15.13 \pm 0.33^{\mathrm{c}}$ \\
Crude fiber (\%) & $21.14 \pm 0.39$ & $0.03 \pm 0.01^{\mathrm{c}}$ & $0.13 \pm 0.02^{\mathrm{a}}$ & $0.42 \pm 0.03^{\mathrm{a}}$ & $0.60 \pm 0.07^{\mathrm{b}}$ \\
Carbohydrates (\%) & $19.24 \pm 0.16$ & $1.85 \pm 0.10^{\mathrm{a}}$ & $1.49 \pm 0.10^{\mathrm{b}}$ & $1.17 \pm 0.20^{\mathrm{b}}$ & $1.16 \pm 0.13^{\mathrm{c}}$ \\
Caloric & $422.21 \pm 0.68$ & $132.71 \pm 0.86^{\mathrm{a}}$ & $148.57 \pm 0.80^{\mathrm{b}}$ & $152.94 \pm 0.94^{\mathrm{c}}$ & $157.87 \pm 0.65^{\mathrm{d}}$ \\
value(Kcal/100g) & & & & & \\
\hline
\end{tabular}

The values shown are means of three replicates. Means are \pm SD having different superscript letters in a row are significantly different $(\mathrm{p}<0.05)$ by Duncan's Multiple Range Test

Table 2: Amino acids profile of the chia seeds and chia enriched yoghurt (CEY)

\begin{tabular}{|c|c|c|c|c|c|}
\hline \multicolumn{6}{|c|}{ Amino acid concentration ( $\mathrm{g} / 100 \mathrm{~g}$ protein) } \\
\hline & Chia seeds & CEY0 & CEY1.5 & CEY2.5 & CEY3.5 \\
\hline \multicolumn{6}{|c|}{ Essential Amino acids } \\
\hline Lysine & $0.73 \pm 0.01$ & $3.22 \pm 0.01^{\mathrm{a}}$ & $4.47 \pm 0.01^{b}$ & $4.78 \pm 0.01^{\mathrm{c}}$ & $5.38 \pm 0.01^{d}$ \\
\hline Histidine & $0.33 \pm 0.01$ & $2.60 \pm 0.01^{\mathrm{a}}$ & $3.40 \pm 0.01^{\mathrm{b}}$ & $3.60 \pm 0.01^{\mathrm{c}}$ & $3.98 \pm 0.01^{d}$ \\
\hline Threonine & $0.40 \pm 0.01$ & $2.65 \pm 0.01^{\mathrm{a}}$ & $3.81 \pm 0.01^{b}$ & $4.10 \pm 0.01^{\mathrm{c}}$ & $4.65 \pm 0.01^{d}$ \\
\hline Valine & $0.62 \pm 0.01$ & $4.01 \pm 0.01^{\mathrm{a}}$ & $4.14 \pm 0.01^{b}$ & $4.18 \pm 0.01^{\mathrm{c}}$ & $4.24 \pm 0.01^{\mathrm{d}}$ \\
\hline Methionine & $0.52 \pm 0.01$ & $1.15 \pm 0.01^{\mathrm{a}}$ & $2.04 \pm 0.01^{\mathrm{b}}$ & $2.26 \pm 0.01^{\mathrm{c}}$ & $2.69 \pm 0.01^{d}$ \\
\hline Isoleucine & $0.54 \pm 0.01$ & $2.56 \pm 0.01^{\mathrm{a}}$ & $3.06 \pm 0.01^{\mathrm{b}}$ & $3.19 \pm 0.01^{\mathrm{c}}$ & $3.43 \pm 0.01^{\mathrm{d}}$ \\
\hline Leucine & $1.02 \pm 0.01$ & $7.56 \pm 0.01^{\mathrm{a}}$ & $8.70 \pm 0.01^{b}$ & $8.99 \pm 0.01^{\mathrm{c}}$ & $9.54 \pm 0.01^{d}$ \\
\hline Phenylalanine & $0.75 \pm 0.01$ & $3.97 \pm 0.01^{\mathrm{a}}$ & $4.10 \pm 0.01^{\mathrm{a}}$ & $4.14 \pm 0.01^{\mathrm{a}}$ & $4.20 \pm 0.01^{\mathrm{a}}$ \\
\hline Tryptophan & $0.07 \pm 0.01$ & ND & ND & ND & ND \\
\hline \multicolumn{6}{|c|}{ Non-essential amino acids } \\
\hline Arginine & $0.74 \pm 0.01$ & $4.80 \pm 0.01^{\mathrm{a}}$ & $6.83 \pm 0.01^{b}$ & $7.34 \pm 0.01^{\mathrm{c}}$ & $8.32 \pm 0.01^{\mathrm{c}}$ \\
\hline Aspartic & $0.58 \pm 0.01$ & $8.63 \pm 0.01^{\mathrm{a}}$ & $9.71 \pm 0.01^{b}$ & $9.98 \pm 0.01^{\mathrm{c}}$ & $10.50 \pm 0.01^{c}$ \\
\hline Serine & ND & $3.02 \pm 0.01^{\mathrm{a}}$ & $3.58 \pm 0.01^{b}$ & $3.72 \pm 0.01^{\mathrm{c}}$ & $3.99 \pm 0.01^{\mathrm{c}}$ \\
\hline Glutamate & $4.36 \pm 0.01$ & $0.09 \pm 0.01^{\mathrm{a}}$ & $8.82 \pm 0.01^{b}$ & $11.00 \pm 0.01^{\mathrm{c}}$ & $15.20 \pm 0.01^{\mathrm{c}}$ \\
\hline Proline & ND & $2.55 \pm 0.01^{\mathrm{a}}$ & $3.05 \pm 0.01^{b}$ & $3.18 \pm 0.01^{\mathrm{c}}$ & $3.42 \pm 0.01^{\mathrm{c}}$ \\
\hline Glycine & ND & $3.65 \pm 0.01^{\mathrm{a}}$ & $5.14 \pm 0.01^{b}$ & $5.52 \pm 0.01^{\mathrm{c}}$ & $6.23 \pm 0.01^{\mathrm{c}}$ \\
\hline Alanine & ND & $4.13 \pm 0.01^{\mathrm{a}}$ & $8.13 \pm 0.01^{b}$ & $9.13 \pm 0.01^{c}$ & $11.05 \pm 0.01^{c}$ \\
\hline Cysteine & ND & $1.19 \pm 0.01^{\mathrm{a}}$ & $2.13 \pm 0.01^{b}$ & $2.37 \pm 0.01^{\mathrm{c}}$ & $2.82 \pm 0.01^{\mathrm{c}}$ \\
\hline Tyrosine & ND & $2.76 \pm 0.01^{\mathrm{a}}$ & $3.56 \pm 0.01^{b}$ & $3.76 \pm 0.01^{\mathrm{c}}$ & $4.14 \pm 0.01^{\mathrm{c}}$ \\
\hline
\end{tabular}

The values shown are means of two replicates. Mean=SD| having different superscript letters in a row are significantly different $(\mathrm{p}<0.05)$ by Duncan's Multiple Range Test

ND means 'not detected' 


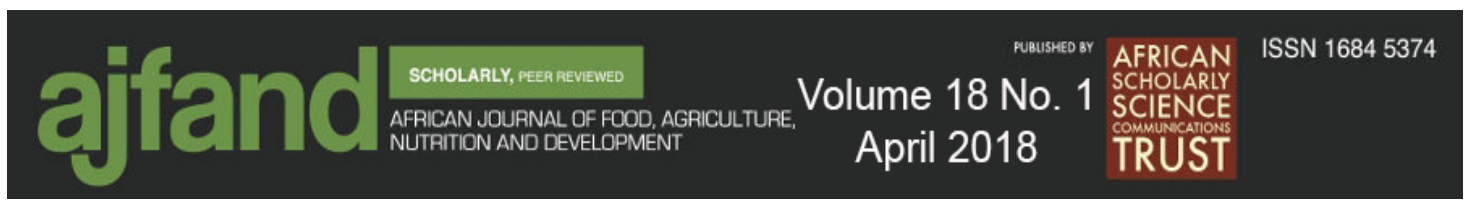

Table 3: Fatty acids composition (\% total fatty acids) of chia seeds and chia enriched yoghurt (CEY)

\begin{tabular}{lrrrrr}
\hline Fatty acids & Chia seeds & \multicolumn{1}{l}{ CEY0 } & CEY1.5 & \multicolumn{1}{l}{ CEY2.5 } & \multicolumn{1}{l}{ CEY3.5 } \\
\hline Caprylic acid & $\mathrm{ND}$ & $0.92 \pm 0.25^{\mathrm{a}}$ & $0.92 \pm 0.15^{\mathrm{b}}$ & $0.88 \pm 0.30^{\mathrm{b}}$ & $0.90 \pm 0.29^{\mathrm{b}}$ \\
Capric & $\mathrm{ND}$ & $2.51 \pm 0.59^{\mathrm{a}}$ & $2.23 \pm 0.35^{\mathrm{a}}$ & $2.20 \pm 0.56^{\mathrm{a}}$ & $2.22 \pm 0.22^{\mathrm{a}}$ \\
Lauric acid & $0.02 \pm 0.15$ & $3.49 \pm 0.26^{\mathrm{a}}$ & $3.09 \pm 0.30^{\mathrm{b}}$ & $3.06 \pm 0.14^{\mathrm{b}}$ & $2.75 \pm 0.17^{\mathrm{c}}$ \\
Myristic acid & $0.05 \pm 0.10$ & $12.35 \pm 0.35^{\mathrm{a}}$ & $12.23 \pm 0.41^{\mathrm{a}}$ & $12.18 \pm 0.59^{\mathrm{a}}$ & $12.07 \pm 0.43^{\mathrm{a}}$ \\
Pentadecanoic acid & $\mathrm{ND}$ & $1.27 \pm 0.30^{\mathrm{a}}$ & $1.20 \pm 0.41^{\mathrm{a}}$ & $1.12 \pm 0.25^{\mathrm{a}}$ & $1.01 \pm 0.30^{\mathrm{a}}$ \\
Palmitic acid & $7.15 \pm 1.40$ & $34.45 \pm 0.91^{\mathrm{a}}$ & $30.19 \pm 0.56^{\mathrm{b}}$ & $29.20 \pm 0.61^{\mathrm{c}}$ & $29.13 \pm 0.55^{\mathrm{c}}$ \\
Palmitoleic acid & $0.03 \pm 0.05$ & $0.29 \pm 0.11^{\mathrm{a}}$ & $0.23 \pm 0.13^{\mathrm{a}}$ & $0.22 \pm 0.41^{\mathrm{a}}$ & $0.22 \pm 0.18^{\mathrm{a}}$ \\
Stearic acid & $3.31 \pm 0.48$ & $11.69 \pm 1.40^{\mathrm{a}}$ & $12.09 \pm 0.96^{\mathrm{b}}$ & $12.36 \pm 0.97^{\mathrm{c}}$ & $12.41 \pm 0.79^{\mathrm{c}}$ \\
Oleic acid & $7.19 \pm 1.33$ & $24.49 \pm 0.77^{\mathrm{a}}$ & $25.23 \pm 0.93^{\mathrm{b}}$ & $25.71 \pm 0.63^{\mathrm{b}}$ & $25.86 \pm 0.78^{\mathrm{b}}$ \\
Linoleic acid & $18.39 \pm 0.99$ & $4.60 \pm 0.40^{\mathrm{a}}$ & $4.72 \pm 0.06^{\mathrm{a}}$ & $4.92 \pm 0.33^{\mathrm{ab}}$ & $5.04 \pm 0.62^{\mathrm{b}}$ \\
a-Linolenic acid & $63.10 \pm 0.41$ & $2.97 \pm 0.62^{\mathrm{a}}$ & $7.28 \pm 0.26^{\mathrm{b}}$ & $7.69 \pm 0.79^{\mathrm{c}}$ & $8.10 \pm 0.35^{\mathrm{d}}$ \\
Arachidic acid & $0.35 \pm 0.30$ & $0.21 \pm 0.41^{\mathrm{a}}$ & $0.25 \pm 0.32^{\mathrm{a}}$ & $0.26 \pm 0.26^{\mathrm{a}}$ & $0.23 \pm 0.23^{\mathrm{a}}$ \\
\hline
\end{tabular}

The values shown are means of three replicates. Means are \pm SD having different superscript letters in a row are significantly different $(\mathrm{p}<0.05)$ by Duncan's Multiple Range Test

ND means 'not detected' 


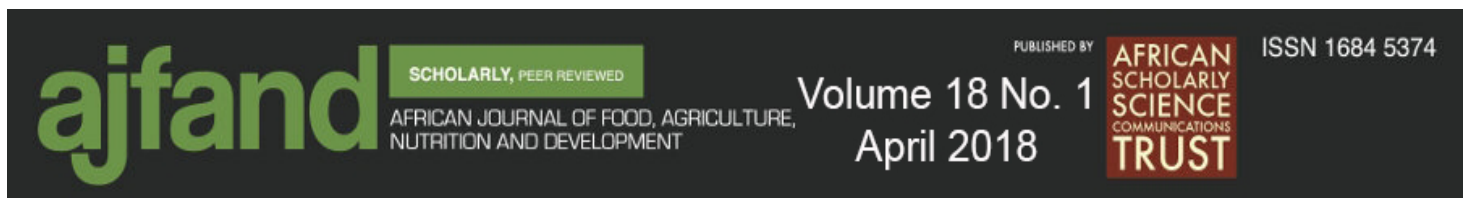

Table 4: Mineral content $(\mathrm{mg} / \mathrm{kg})$ of the chia seeds and yoghurt samples

\begin{tabular}{lrrlrl}
\hline Sample & \multicolumn{1}{l}{ Chia seeds } & \multicolumn{1}{l}{ CEY0 } & \multicolumn{1}{l}{ CEY1.5 } & \multicolumn{1}{l}{ CEY2.5 } & \multicolumn{1}{l}{ CEY3.5 } \\
\hline $\mathrm{Ca}$ & $1293.15 \pm 0.20$ & $6869.21 \pm 0.01^{\mathrm{a}}$ & $7420.32 \pm 0.03^{\mathrm{b}}$ & $7912.36 \pm 0.11^{\mathrm{c}}$ & $8017.21 \pm 0.07^{\mathrm{d}}$ \\
$\mathrm{K}$ & $700.57 \pm 0.04$ & $690.47 \pm 0.01^{\mathrm{a}}$ & $694.29 \pm 0.01^{\mathrm{a}}$ & $707.20 \pm 0.01^{\mathrm{a}}$ & $745.10 \pm 0.01^{\mathrm{a}}$ \\
$\mathrm{Mg}$ & $225.93 \pm 0.01$ & $416.51 \pm 0.01^{\mathrm{a}}$ & $410.75 \pm 0.01^{\mathrm{a}}$ & $420.92 \pm 0.01^{\mathrm{a}}$ & $423.68 \pm 0.01^{\mathrm{a}}$ \\
$\mathrm{Fe}$ & $9.14 \pm 0.01$ & $41.20 \pm 0.01^{\mathrm{a}}$ & $37.79 \pm 0.01^{\mathrm{a}}$ & $37.70 \pm 0.01^{\mathrm{a}}$ & $37.54 \pm 0.01^{\mathrm{b}}$ \\
$\mathrm{Zn}$ & $6.68 \pm 0.01$ & $6.25 \pm 0.01^{\mathrm{a}}$ & $7.07 \pm 0.01^{\mathrm{a}}$ & $6.85 \pm 0.01^{\mathrm{a}}$ & $8.33 \pm 0.01^{\mathrm{a}}$ \\
$\mathrm{Mn}$ & $7.56 \pm 0.01$ & $26.53 \pm 0.04^{\mathrm{a}}$ & $25.72 \pm 0.01^{\mathrm{a}}$ & $27.11 \pm 0.01^{\mathrm{a}}$ & $26.64 \pm 0.01^{\mathrm{a}}$ \\
$\mathrm{P}$ & $116.30 \pm 0.01$ & $370.73 \pm 0.01^{\mathrm{a}}$ & $362.27 \pm 0.01^{\mathrm{a}}$ & $390.12 \pm 0.01^{\mathrm{b}}$ & $397.25 \pm 0.02^{\mathrm{b}}$
\end{tabular}

The values shown are means of two replicates. Mean $\pm \mathrm{SD}$ having different superscript letters in a row are significantly different $(\mathrm{p}<0.05)$ by Duncan's Multiple Range Test

ND 'means not detected"

CEY- Chia enriched yoghurt 


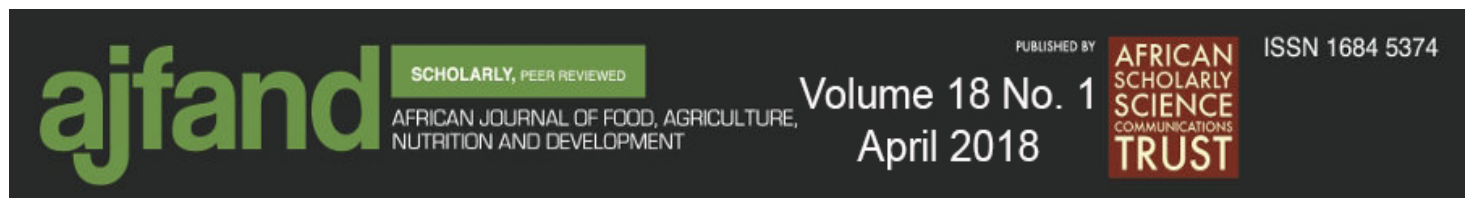

\section{REFERENCES}

1. Noah E “Dairy Industry in Kenya,” Nairobi, 2005.

2. Puteri NE, Pratama $\mathbf{F}$ and $\mathbf{V}$ Anantawat Effects of formulation on characteristics of probiotic yogurt enriched by Gac and Passion fruits Khon Kaen Agric. J. 2014; 42: 248-263.

3. Abdi El-Aziz ME, El-Gammal RE, Abo-srea MM and FI Youssf Antioxidant and antimicrobial activity of pomegranate ( Punica granatum L .) fruit peels extract on some chemical, microbiological and organoleptical properties of yoghurt during storage. Journal of Food and Dairy Science.Mansoura Univeristy, Egypt, 2013.

4. Marhamatizadeh MH, Ehsandoost $\mathbf{E}$ and $\mathbf{P}$ Gholami The influence of Green Tea ( Camellia sinensis L .) Extract on characteristic of probiotic bacteria in milk and yoghurt during fermentation and refrigerated storage, Islamic Azad University, 2013.

5. Goyat J, Suri SJ and P Sukhneet Chia Seed ( Salvia hispanica L.) - A New Age Functional Food Amity University, (India), 2016.

6. Segura-campos MR, Ciau-solís N, Rosado-rubio L, Chel-guerrero L and D Betancur-ancona Chemical and Functional Properties of Chia Seed ( Salvia hispanica L .) Gum," Int. J. Food Sci. 2014; 1155;1-5.

7. Ullah R, Nadeem M and M Imran Omega-3 fatty acids and oxidative stability of ice cream supplemented with olein fraction of chia (Salvia hispanica L.) oil," Lipids Health Dis.2017; . 16, (34):1-8.

8. AOAC. Official Methods of Analysis. Association of Official Analytical Chemists, 18th Edition. Washington DC, 2005.

9. Al-abdulkarim BO, Osman MS and M El-nadeef Determination of chemical composition, and storage on dried fermented goat milk product ( Oggtt ) $J$. Saudi Soc. Agric. Sci. 2013;12:161-166.

10. Ihemeje A, Nwachukwu CN and CC Ekwe Production and quality evaluation of flavoured yoghurts using carrot, pineapple, and spiced yoghurts using ginger and pepper fruit Afri. J. Food Sci. 2015; 9:163-169.

11. Coelho MS and MDM Salas-mellado Chemical characterization of chia (Salvia hispanica L .) for use in food products J. Food Nutr. Res., 2014; 2:263269. 
12. Kim SS, Rahimnejad S, Song JW and KJ Lee Comparison of growth performance and whole-body amino acid composition in red seabream (Pagrus major) fed free or dipeptide form of phenylalanine Asian Aust. J. Anim. Sci., 2012; 25:1138-1144.

13. Gul S and M Safdar Proximate Composition and Mineral Analysis of Cinnamon Pakistan J. Nutr. 2009; 8:1456-1460.

14. Gerdel RW The colorimetric determination of total phosphorus in plant solutions Ohio J. Sci. 1928; 28:229-235.

15. Ndife J, Idoko F and R Garba Production and quality assessment of functional yoghurt enriched with coconut," Int. J. Nutr. Food Sci. 2014; 3:545-550.

16. Muñoz LA, Cobos A, Diaz $\mathbf{O}$ and J Aguilera Chia seeds: Microstructure, mucilage extraction and hydratio J. Food Eng. 2012; 108:216-224.

17. Gemede HF, Haki GD, Beyene F, Woldegiorgis AZ and SK Rakshit Proximate, mineral, and antinutrient compositions of indigenous Okra ( Abelmoschus esculentus ) pod accessions: implications for mineral bioavailability Wollega University, 2016.

18. Løvik M, Marchelli R, Martin A and B Moseley Opinion on the safety of " Chia seeds ( Salvia hispanica L .) and ground whole chia seeds as a food ingredient Eur. Food Saf. Auth. 2009; 996: 1-26.

19. Ixtaina VY, Martínez ML, Spotorno V, Mateo CM, Maestri DM, Diehl BWK, Nolasco SM and MC Tomás Characterization of chia seed oils obtained by pressing and solvent extraction," J. Food Compos. Anal., 2011; 4:166-174.

20. Ayerza $\mathbf{W}$ and $\mathbf{R}$ Coates Influence of environment on growing period and yield, protein, oil and linolenic content of three chia (Salvia hispanica L.) selections Ind. Crops and Products 2009; 30: 321-324.

21. Marinescu A and F Pop "Variation in physicochemical parameters of probiotic yogurt during refrigeration storage," Carpathian J. Food Sci. Technol., 2009; 1(2):18-26.

22. Saint-Eve A, Levy C, Le Moigne M and VSI Ducruet "Quality changes in yogurt during storage in different packaging materials," Food Chem., 2008; 110: $285-293$.

23. Ehirim FN and EN Onyeneke Physicochemical and organoleptic properties of yoghurt manufactured with Cow milk and Goat milk Nat. Appl. Sci. 2013; 4: 245-252. 


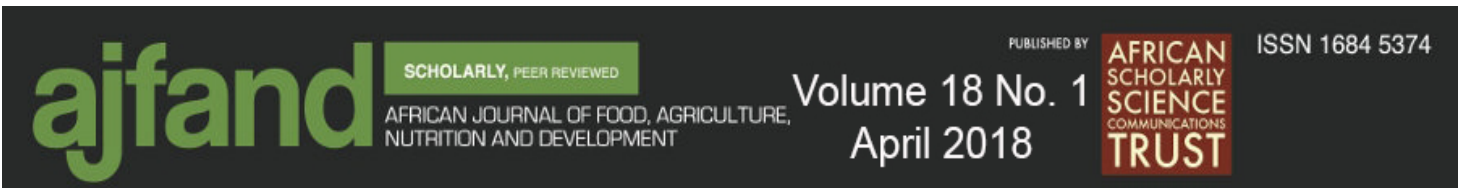

24. Ullah R, Nadeem M, Khalique A, Imran M, Mehmood S, Javid A and J Hussain Nutritional and therapeutic perspectives of Chia (Salvia hispanica L.): a review J. Food Sci. Technol. 2016; 53:1750-1758.

25. Anderson JW, Baird P, Davis RH, Jr, Ferreri S, Knudtson M, Koraym A, Waters V and CL Williams Health benefits of dietary fiber Nutr. Rev. J. 2009; 67:188-205.

26. Akoh CC and DB Min Food lipids : chemistry, nutrition, and biotechnology. New York: CRC Press, 2008.

27. Coorey R, Grant A and V Jayasena Effects of Chia Flour Incorporation on the Nutritive Quality and Consumer Acceptance of Chips J. Food Res. 2012; 1: 85-95.

28. Imran M, Nadeem M, Manzoor MF, Javed A, Ali Z, Akhtar MN, Ali M and $Y$ Hussain Fatty acids characterization, oxidative perspectives and consumer acceptability of oil extracted from pre-treated chia (Salvia hispanica L .) seeds Lipids Health Dis., 2016; 15:1-13.

29. NCBI "PubChem Compound Database," 2004.Retrieved on 15 $5^{\text {th }}$ March, 2017.

30. Ayerza R and W Coates Chia seeds: New source of omega-3 fatty acids, natural antioxidants, and dietetic fiber. Tucson, Arizona, USA: Southwest Center for Natural Products Research and Commercialization, Office of Arid Lands Studies, 2001.

31. Amellal-chibane $\mathbf{H}$ and $\mathbf{S}$ Benamara Total contents of major minerals in the nature yoghurt and in the yoghurts with the date powder of three dry varieties and Biodiversity Am. J. Food Nutr. 2011;1: 74-78.

32. Oscar A, Stmin N and MR Robert Yogurt and gut function Amerian J. Clin. Nutr.2004; 80: 246-256.

33. Elinge CM, Muhammad A, Atiku FA, Itodo AU, Peni IJ and OM Sanni Proximate, mineral and anti-nutrient composition of pumpkin (Cucurbitapepo L) seeds extract Int. J. Plant Res., 2012; 2:146-150.

34. FNB DRI Dietary Reference Intakes for Calcium, Phosphorus, Magnesium, Vitamin D, and Fluoride 1997. Retrieved on $23^{\text {rd }}$ February, 2017.

35. Lee K, Kim K, Kim H, Seo J and S Song Association between dietary calcium and phosphorus intakes, dietary calcium / phosphorus ratio and bone mass in the Korean population Nutr. J. 2014; 114:1-8. 